\title{
Recent updates on immunological, pharmacological, and alternative approaches to combat COVID-19
}

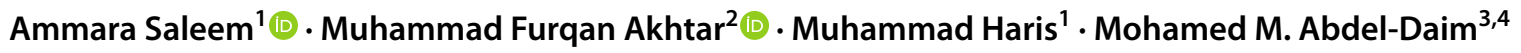

Received: 22 May 2021 / Accepted: 29 June 2021 / Published online: 30 July 2021

(c) The Author(s), under exclusive licence to Springer Nature Switzerland AG 2021

\begin{abstract}
The pandemic coronavirus disease 2019 (COVID-19) is instigated by severe acute respiratory syndrome coronavirus 2 (SARS-CoV-2) that is mainly transmitted via the inhalation route and characterized by fever, coughing and shortness of breath. COVID-19 affects all age groups with no single cure. The drug discovery, manufacturing, and safety studies require extensive time and sources and, therefore, struggled to match the exponential spread of COVID-19. Yet, various repurposed drugs (antivirals, immune-modulators, nucleotide analogues), and convalescent plasma therapy have been authorized for emergency use against COVID-19 by Food and Drug Administration under certain limits and conditions. The discovery of vaccine is the biggest milestone achieved during the current pandemic era. About nine vaccines were developed for human use with varying claims of efficacy. The rapid emergence of mutations in SARS-CoV-2, suspected adverse drug reactions of current therapies in special population groups and limited availability of drugs in developing countries necessitate the development of more efficacious, safe and cheap drugs/vaccines for treatment and prevention of COVID-19. Keeping in view these limitations, the current review provides an update on the efficacy and safety of the repurposed, and natural drugs to treat COVID-19 as well as the vaccines used for its prophylaxis.
\end{abstract}

Keywords COVID-19 · Corona virus · Vaccine $\cdot$ Antiviral $\cdot$ Convalescent plasma therapy

\section{Introduction}

The novel coronavirus disease (COVID-19) is instigated by severe acute respiratory syndrome coronavirus 2 (SARSCoV-2) (Yuan et al. 2020). In November 2019, Wuhan became the emerging key zone of a novel coronavirus outbreak that was characterized by upper and lower respiratory

Ammara Saleem

amarafurqan786@hotmail.com

$\triangle$ Muhammad Furqan Akhtar

furqan.pharmacist@gmail.com

1 Department of Pharmacology, Faculty of Pharmaceutical Sciences, Government College University Faisalabad, Faisalabad, Pakistan

2 Riphah Institute of Pharmaceutical Sciences, Riphah International University, Lahore Campus, Lahore, Pakistan

3 Pharmacology Department, Faculty of Veterinary Medicine, Suez Canal University, Ismailia 41522, Egypt

4 Department of Pharmaceutical Sciences, Pharmacy Program, Batterjee Medical College, P.O. Box 6231, Jeddah 21442, Saudi Arabia tract distress and proceeded to deleterious systemic manifestation and premature mortality. It is notorious for its exponential rise in the number of infected individuals of any age. This coronavirus was isolated and labelled as the novel virus corona disease 2019 (nCOV-2019) by Chinese scientists followed by its genome sequencing in January 2020. It caused deaths of more than 1800 while infected more than 70,000 individuals within the first 5 days of this COVID-19 that was latterly stated as a global pandemic by the World Health Organization (WHO) (Lu et al. 2020; Lai et al. 2020). To date, about 162 million people are infected and 33 million people have died owing to this malicious infection. It is mainly transmitted via inhalation route due to sneezing droplet of infective patient (Jiang et al. 2021).

Novel coronavirus (family: coronaviridae; genera; $\beta$-coronavirus) is a greatly varied, enclosed, and singlestranded positive-sense RNA virus that has nucleocapsid with helical symmetry (Khan et al. 2020). Coronavirus has spikes like a crown on its outermost surface, tiny in size (dia: 65-125 nm), and 26-32 kbs length of single-stranded RNA (Shereen et al. 2020; Jiang et al. 2021). 
The positive patient expresses either symptom, that of various severity or is symptomless depending on different factors as immunity and a variant of COVID-19. The most prevailing symptoms include fever, coughing, shortness of breath, diarrhea, and vomiting. The clinical evaluation of most patients has shown a normal or low level of WBCs and lymphocytopenia. But in serious conditions, C-reactive protein, neutrophil count, blood urea, D-dimer and creatinine levels are profoundly raised. Additionally, upregulation of inflammatory mediators, i.e. interleukin (IL)-6, and tumor necrosis factor- $\alpha$ contribute to the immune-compromised status of the patients (Quer et al. 2021). People with underlying diseases such as chronic obstructive pulmonary disease, diabetes, cardiovascular disease and elderly are highly prone to develop respiratory distress syndrome, coagulation, and septic shock that are hard to correct even leading to the death (Wu et al. 2021).

\section{Pathogenesis of COVID-19}

The association of S protein with host cell surface receptors initiates virus infection. The cellular serine proteases TMPRSS2 will cleave the S protein into S1 and S2 (Walls et al. 2020). The C-terminal domain (CTD) of S1 particularly attaches to the receptor of host cell angiotensin-converting enzyme 2 (ACE2) and induces the conformational change of S2 that instigates the release of virus's genome into the cytoplasm (Wang et al. 2020c). The viral RNA prompts replication and transcription, latterly, newly ensemble viruses are discharged out extracellularly via exocytosis (Fehr et al. 2015; Ray and Maunsell 2011). The target receptor sites for COVID-19 infection in host body are presented in Table 1

The virus disseminates downward to the RT causing a vigorous innate immune response. The level of inflammatory chemokines (CXCL10) and cytokines is increased in bronchial airways which cause the recruitment of leukocytes, monocytes, eosinophils, natural killer (NK) cells and ILs that trigger gigantic inflammatory reaction (Mason 2020).
The whole process affects gas exchange units of the lungs, which cause severe difficulty in breathing. High expression of inflammatory mediator's causes narrowing of the airways and unwanted robust innate immune response which result in fever, cough, and pneumonia-like symptoms.

It has been documented in COVID-19 infected patients that there is cerebral interference may occur in the early or later stage of the infection. The appearance of the COVID-19 virus in the general circulation allows it to reach the cerebral circulation, where even the virus spike protein interacts with ACE2 receptors expressed in capillary endothelium which further leads to harm the vessels and draw access to the brain. In the neuronal tissues, it interacts with ACE2 specific receptors in neurons, triggering a cycle of viral budding and neuronal damage without causing substantial inflammation (Palasca et al. 2018; Baig et al. 2020; Wang et al. 2020a). The endothelium of cerebral capillary ruptures followed by bleeding inside the cerebral tissue, may prove fatal to COVID-19 patients.

The multifold transmission of different variants of COVID-19 emerges the intense demand for curative/prophylactic therapy to combat that dilemma of the present era. To date, there are few reports on possible preventive approaches or vaccine candidates. Clinical trials (CT) for COVID-19 therapies are being conducted, though, data from broad randomized clinical trials (RCT) are still deficient (Felsenstein et al. 2020). Due to time-consuming challenges of developing, testing, and manufacturing new medications, repurposing of proven medicinal remedies such as anti-inflammatory, antiviral, and anticoagulants offer a pragmatic alternative for symptomatic treatment of the COVID-19 infection (Harrison 2020).

Currently, antiviral, immune-modulators, nucleoside analogues, neuraminidase inhibitors, protease inhibitors, and antimalarial drugs are some of the drug options used in the treatment of this fatal infection (Reche et al. 2020). Medicinal plants and their secondary metabolites such as flavonoids have exhibited substantial antiviral activity for different human viruses, including human immune deficiency virus

Table 1 Mechanism of target receptors sites and their actions in Covid-19 virus in host

\begin{tabular}{llll}
\hline Target receptor & Activity & $\begin{array}{l}\text { Target } \\
\text { human } \\
\text { cells }\end{array}$ & References \\
\hline Aminopeptidase N (APN) & Aids S protein mediated entry of virus into host cells & URT & (Li et al. 2018; Wong et al. 2017) \\
Angiotensin converting enzyme 2 (ACE2) & $\begin{array}{l}\text { Aids entry of coronavirus into host, replication and } \\
\text { normal function of ACE2 is blocked }\end{array}$ & URT & (Jia et al. 2005; Wong et al. 2017) \\
O-acetylated sialic acid & Aids entry into the cell through S1 protein & URT & (Hulswit et al. 2019) \\
ACE2 & Aids entry of virus into cell & LRT & (Hoffmann et al. 2020) \\
Dipeptidyl peptidase 4 (DPP4) & Acts as the entry gate for virus spike protein in the & LRT & (Pitocco et al. 2020) \\
& host cell & & \\
\hline
\end{tabular}

Upper (U), respiratory tract: RT, Lower: L 
(HIV), Middle East respiratory syndrome (MERS), hepatitis $\mathrm{C}$ virus, (HCV), SARS, and influenza viruses. Moreover, they have shown positive response in the management of COVID-19 (Adhikari et al. 2021). Presently, more than 300 COVID-19 vaccine projects are under different phases, of which 40 are evaluated in CT, 10 in Phase III and three have completed Phase III with positive consequences (Forni and Mantovani 2021); (Lurie et al. 2020). The current literature focuses on various available therapeutic options as well vaccines against COVID-19.

\section{Brief review of COVID-19 available therapies}

Various therapeutic options for COVID-19 are explored in Fig. 1.

\section{Antiviral drugs}

The viral life cycle steps as well as virus entry and immune response are resilient targets for therapeutic drugs. The spike protein, ACE2, TMPRSS2, chymotrypsin like protease (3CLpro), RNA dependent RNA polymerase (RdRp), and papain-like protease (PLpro) are deliberated as chief targets for antiviral drugs against COVID-19 due to their high catalytic action and similarity with SARS-CoV-2 (Tallei et al. 2020). While certain mutations allow the virus to tightly affix to the host receptor and boost receptor transmissibility, which probably upsurge the infection transmission/ prevalence. When the virus is inhaled, it comes in contact with epithelial cells of the nasal cavity and starts replicating and produce an innate immune response to a limited extent (Mason 2020).

Remdesivir (wide spectrum), an adenosine nucleotide analogue and a wide spectrum antiviral drug developed in 2014 for the treatment of Ebola Virus (EBV), is now being used for COVID-19 infection by the U.S. Food and Drug Administration (FDA). Remdesivir stops replication and showed effective results in the treatment of later stages of COVID-19. It incorporates in single-stranded RNA of corona virus by polymerase enzyme, inhibit the addition of more RNA subunits and obstruct genome replication (Stebbing et al. 2020) as shown in Fig. 2.

Favipiravir (synthetic prodrug), originally a purine nucleotide, effectively inhibits RNA dependent RNA polymerase (RdRp) and averts virus production. It is used against influenza and EBV viruses and has shown broad activity against many other RNA virus (SARS-CoV-2) (Udwadia et al. 2021).

The disulfiram, a disulphide, an authorized medicine for alcohol misuse, is widely acclaimed to block the MERS and SARS PLpro, now present a potential role against SARSCov2. It inhibits the release of viral genome by hindering the papain-like protease in SARS-CoV2 (Majumder and Minko 2021; Beck et al. 2020). The combination of disulfiram/ ebselen and remdesivir is found effective against COVID19 by hindering replication step in in vitro study (Chen et al. 2021). This combination is a multitarget strategy effective against all types of corona viruses with conserved zinc $\left(\mathrm{Zn}^{+}\right)$ ejection site.

Various therapeutic drugs target sites and action in COVID-19 are illustrated in Fig. 2 and Table 2.

\section{Immuno-modulators}

Tocilizumab (TCZ), anti-IL-6 monoclonal antibody, is now used for COVID-19 patients (Luo et al. 2020b). It blocks cytokine storm and potentially stabilizes the condition of patients. But it is preferred to use for critically ill patients in repeated doses (Wu et al. 2021).

Fig. 1 Therapeutic strategy for COVID-19
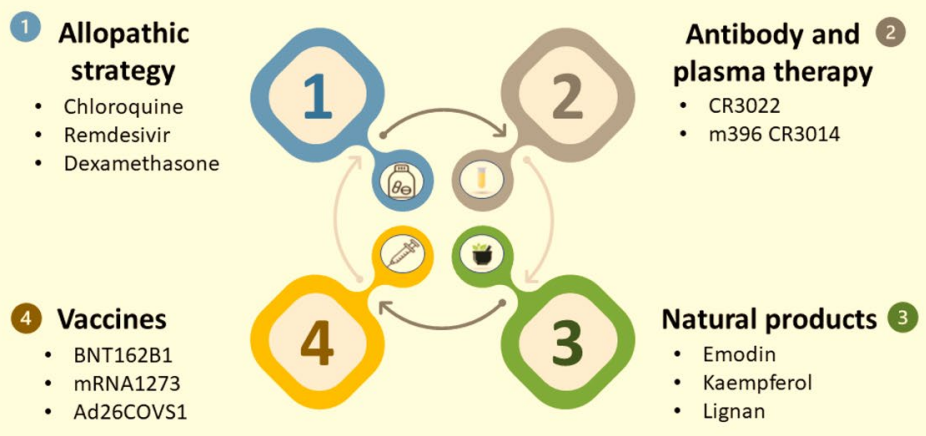


\section{1-Target ACE2 receptors}

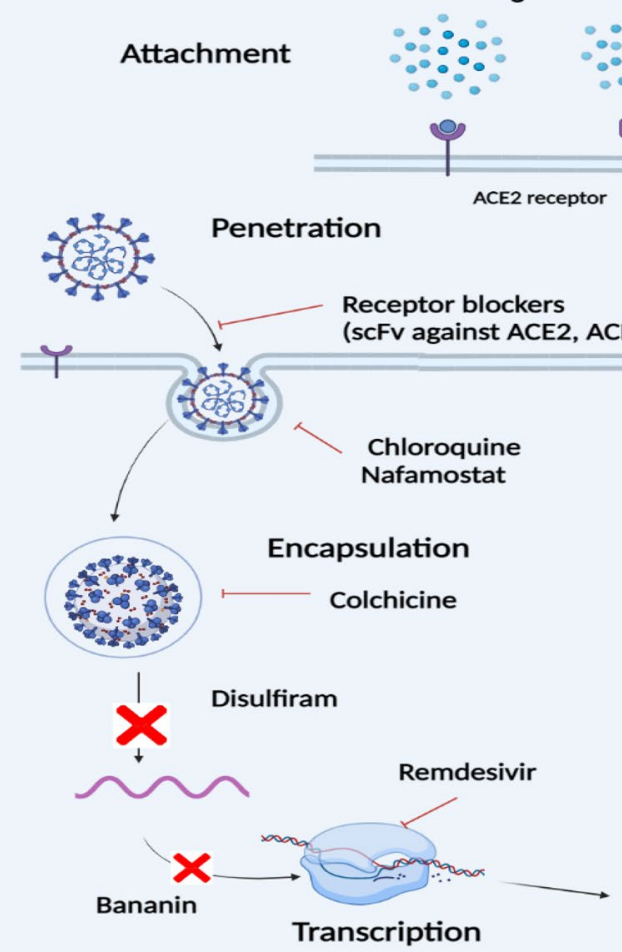

2- Target RBD of spike protein
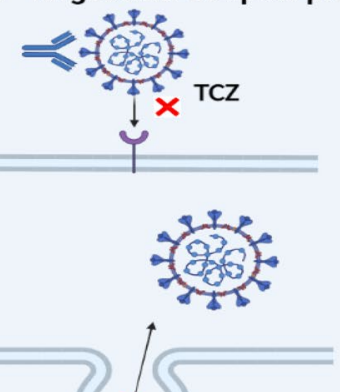

Chloroquine

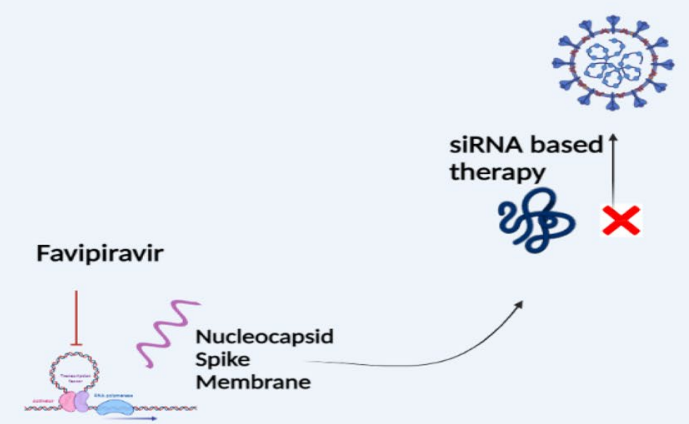

Fig. 2 Various allopathic treatments of COVID-19. Targeting viral entry mechanisms, possible methods for blocking ACE2 receptors, and antiviral drugs in replication stage [modified from (Majumder and Minko 2021)]. $s c F v$ single-chain variable fragment, $T C Z$ tocilizumab

Table 2 Current allopathic therapies and their actions and potential adverse effects in COVID-19

\begin{tabular}{|c|c|c|c|c|}
\hline $\begin{array}{l}\text { Drug } \\
\text { class }\end{array}$ & Therapeutic drug & Actions & Adverse effects & References \\
\hline Antimalarial & Chloroquine phosphate & $\begin{array}{l}\text { Glycosylation inhibitor } \\
\text { Proteolytic, inhibition of } \\
\text { cytokines production, } \\
\text { autophagy, lysosomal and } \\
\text { host cell activity }\end{array}$ & $\begin{array}{l}\text { Cramps in the abdomen, diar- } \\
\text { rhea, anorexia } \\
\text { CVD symptoms, hypogly- } \\
\text { cemia, retinal damage, } \\
\text { neuropsychiatric toxicity, } \\
\text { Idiosyncratic reactions }\end{array}$ & (Vijayvargiya et al. 2020) \\
\hline \multirow[t]{2}{*}{ Antiviral } & Remdesivir & Inhibition of RNA polymerase & $\begin{array}{l}\text { Transaminases elevation, kid- } \\
\text { ney damage }\end{array}$ & (Stebbing et al. 2020) \\
\hline & Favipiravir & Inhibition of RNA polymerase & $\begin{array}{l}\text { Hyperuricemia, diarrhoea, } \\
\uparrow \text { Transaminases, } \downarrow \text { Neutrophil } \\
\text { count }\end{array}$ & (Udwadia et al. 2021) \\
\hline Monoclonal antibody & Tocilizumab & $\begin{array}{l}\text { Block IL-6 receptor alpha } \\
\text { subunit }\end{array}$ & $\begin{array}{l}\text { GIT disorders, skin/subcutane- } \\
\text { ous infections and altered } \\
\text { liver enzymes }\end{array}$ & (Luo et al. 2020b) \\
\hline Anti-HIV & Lopinavir/ritonavir & $\begin{array}{l}\text { Inhibit 3C-like proteinase } \\
\text { (3CLpro) and papain-like } \\
\text { proteinase (PLpro) resulted } \\
\text { in immature virus particle in } \\
\text { COVID-19 }\end{array}$ & $\begin{array}{l}\text { GIT intolerance, pancreatitis, } \\
\text { abnormalities in cardiac con- } \\
\text { duction, hepatotoxicity }\end{array}$ & (Consortium WST 2021) \\
\hline Antiprotease & Disulfiram & Papain like protease inhibitor & Hypotension, tachycardia & (Majumder and Minko 2021) \\
\hline
\end{tabular}

Gastrointestinal: GIT, cardiovascular disorders: CVD 
The TCZ in combination with lopinavir and methylprednisolone is also suggested for the treatment of COVID-19 patients especially in severe cases (David J Cennimo 2020). IL-6 is a multipurpose cytokine that is involved in B-cell differentiation, thrombopoiesis stimulation, protein synthesis and also bone resorption. It prevents the interaction of interleukin with signal transducer glycoprotein (130 complexes) and IL-6R. As a result, after involving the Janus-kinasesignal transducer and activator of transcription proteins signalling pathway, it inhibits cis and trans signalling cascades (Biggioggero et al. 2019).

Corticosteroids are also used in the management of COVID-19. They block inflammatory storm especially in lungs, which otherwise could lead to acute lung injury and acute breathing distress syndrome (ARDS) (Russell et al. 2020). Dexamethasone (Dex) is the very first lifesaving drug showed therapeutic effectiveness in COVID-19. In the largest COVID-19 RCT, the so-called RECOVERY trial, six interventions were under evaluation including Dex, hydroxychloroquine, Azithromycin, anti-HIV drug combination lopinavir-ritonavir, TCZ, and healed patient convalescent plasma. No clinical benefit was reported for hydroxychloroquine and lopinavir-ritonavir in hospitalized patients in the first and third statements published by the RECOVERY chief investigators. The second quote indicated Dex $(6 \mathrm{mg} /$ day; orally or intravenous infusion administered for 10 days) reduced the numbers of COVID-19 deaths in intensive care unit (ICU) patients with oxygen therapy (35\%). The death rate was decreased 20\% under oxygen therapy. Moreover, nanodelivery of Dex is assumed to be more efficacious than conventional in COVID-19 patients (Lammers et al. 2020).

Chloroquine, an antimalarial agent with anti-inflammatory and immunomodulatory effects, had acquired great attention as a possible therapeutic alternative for COVID19 treatment (Vijayvargiya et al. 2020).

\section{Antibody and convalescent plasma (CP) therapy}

The CP therapy was suggested by the FDA (21 Apr 2021) in emergency use authorization (EUA) for hospitalized COVID-19 patients. The high titer CP was recommended in the EAU against COVID-19 in hospitalized and immune deficient patients, nevertheless use of low titer CP is restricted in EUA (http://www.ncbi.nlm.nih.gov). The generation of recombinant human monoclonal antibody (mAb) provides a path to neutralize COVID-19 virus by interacting with the spike protein (S glycoprotein) present on its surface. CR3022, SARS-CoV specific antibody, binds to the receptor-binding domain (RBD), recognized as a therapeutic candidate against COVID-19 infection (Wang et al. 2020a). Other monoclonal antibodies like 47D11, m396 and CR3014 are also used for the treatment of corona virus infection (Zhang and Liu 2020; Yuan et al. 2020).

\section{Natural products}

The medicinal plants and phytocomponents exhibited synergistic effects against the COVID-19 and boosted the immune system such as Citrus limon, Nigella sativa, Withania somnifera, etc. Previous studies reported the immune booster effect of these plants in COVID-19 infection that acted by binding and hindering to 3CLpro, main protease (Mpro), papain-like protease (PLpro), and spike protein in COVID19 (Tallei et al. 2020). The edible foods such as cinnamon, pepper, olive, black nightshade, passion fruit, and grapes are also effective in prophylaxis and treatment of COVID-19. These plants have ACE2 inhibition activity and have been used in coronavirus patients with comorbidities of hypertension and diabetes (da Silva Antonio et al. 2020; DaskayaDikmen et al. 2017). Some plants have been used as 3C-like protease (3CLpro) inhibitors such as lemon, balm, lavender, geranium, basil, cinnamon, and ginger.

Quercetin, strong antioxidant, is a flavonoid derivative isolated from several fruits and vegetables such as Foeniculum vulgare, and Allium cepa. It blocked (82\%) SARS-CoV protease (Huang et al. 2020). It showed antiviral properties against SARS-CoV-2 in docking study using 3CLpro and other crucial targets (Tallei et al. 2020). Previously, it was reported that quercetin binds to spike protein, ACE2, RdRp, and PLpro, which assured its anti-SARS-CoV-2 potential.

Andrographolide (diterpene), an efficient antiviral, is extracted from Andrographis paniculata and binds to spike protein, ACE2, 3CLpro, RdRp, and PLpro (Kishore et al. 2017) that indicated its possible efficacy against COVID-19. Glycyrrhizic acid, a polyphenol derived from Glycyrrhiza glabra root binds to ACE2 receptor hence effective against SARS-CoV, and SARS-CoV-2 (Luo et al. 2020a). Furthermore, it inhibits immune hyperactivation and production of cytokine storm (He et al. 2020). Baicalin, is a flavone glycoside and non-peptidomimetic inhibitors of SARS-CoV-2 3CLpro (Chen et al. 2017).

Patchouli alcohol (PA), a sesquiterpene has antiviral, antiinflammatory, immunomodulatory, antioxidant, and antitumor properties (Hu et al. 2017). The molecular docking showed the binding of PA to SARS-CoV-2 related targets and explored the satisfactory binding of PA to RdRp which assured its antiviral effect.

Luteolin, a naturally occurring flavonoid, has anti-cancer, anti-inflammatory, antioxidant, antiviral, and heart-protective properties (Fasuan et al. 2018). SARS-CoV 3CLpro was inhibited by luteolin derived from Torreya Nucifera (Ryu et al. 2010). Various phytochemicals and their target sites for COVID-19 therapy are mentioned in Table 3 and Fig. 3. 
Table 3 Natural compounds and their potent mechanism of action against COVID-19

\begin{tabular}{|c|c|c|c|c|}
\hline Natural Compounds & Class & Source & Mechanism of action & References \\
\hline Quercetin & Flavonol & Dysosma pleiantha & $\begin{array}{l}\text { Hinders }(\times) \text { CLp and block virus } \\
\text { entry into the cell }\end{array}$ & $\begin{array}{l}\text { (Nguyen et al. 2012; Al Hamdany } \\
\text { et al. 2019) }\end{array}$ \\
\hline Andrographolide & Diterpenoid & Andrographis paniculata & $\begin{array}{l}\times \text { CLp and virus-induced } \\
\text { stimulation of RLRs signalling } \\
\text { pathway }\end{array}$ & $\begin{array}{l}\text { (Enmozhi et al. 2021; Rao et al. } \\
\text { 2004; Malik et al. 2021) }\end{array}$ \\
\hline Glycyrrhizic acid & Polyphenols & Glycyrrhiza glabra & $\begin{array}{l}\times \text { replication and permeation of } \\
\text { the virus }\end{array}$ & $\begin{array}{l}\text { (Luo et al. 2020a; Petramfar et al. } \\
\text { 2020; Nazari et al. 2017) }\end{array}$ \\
\hline Baicalin & Flavone glycoside & Radix Scutellariae & $\times \mathrm{CLp}$ & (Su et al. 2020; Okoshi et al. 2021) \\
\hline Patchouli alcohol & Sesquiterpene alcohol & Pogostemon cablin & $\begin{array}{l}\text { Bind with RdRp and produce } \\
\text { inhibitory effects }\end{array}$ & (Yu et al. 2019; Xu et al. 2017) \\
\hline Luteolin & Flavone & $\begin{array}{l}\text { Cuminum cyminum } \\
\text { Torreya nucifera }\end{array}$ & $\begin{array}{l}\times \text { CLp and blocks viral replica- } \\
\text { tion in early stage of contami- } \\
\text { nation }\end{array}$ & $\begin{array}{l}\text { (Yan et al. 2019; Kempuraj et al. } \\
\text { 2021; Goodarzi et al. 2020) }\end{array}$ \\
\hline Hesperidin & Flavanone glycoside & Citrus sinensis & $\times \mathrm{CLp}$ & $\begin{array}{l}\text { (Joshi et al. 2021; Sim 2019; Selmi } \\
\text { et al. 2017) }\end{array}$ \\
\hline Emodin & Anthraquinone & Aloe vera & $\begin{array}{l}\text { Blocks the SARS-CoV2 spike } \\
\text { protein and ACE2 interaction } \\
\text { and reduce virus release }\end{array}$ & $\begin{array}{l}\text { (Schwarz et al. 2011; Kumar et al. } \\
\text { 2017) }\end{array}$ \\
\hline Resveratrol & Phenol & Vitis vinifera & $\begin{array}{l}\times \text { RNA and nucleocapsid expres- } \\
\text { sion }\end{array}$ & $\begin{array}{l}\text { (Lin et al. 2017; Hasan and Bae } \\
\text { 2017) }\end{array}$ \\
\hline Kaempferol & Flavanol & Dysosma pleiantha & $\times 3$ a channel protein & (Karuppaiya and Tsay 2020) \\
\hline Lignan & Polyphenols & Phyllanthus tenellus Roxb & $\times$ virus replication and CLp & (Lee et al. 2015; Szopa et al. 2021) \\
\hline Betulinic acid & Triterpenoid & Yarrowia lipolytica & $\times$ virus replication and CLp & $\begin{array}{l}\text { (Hordyjewska et al. 2019; Jin et al. } \\
\text { 2019) }\end{array}$ \\
\hline Tanshinone & Diterpene quinone & Salvia xantocheila & $\times$ CLp and PLpro & $\begin{array}{l}\text { (Hirai et al. 2015; Fotovvat et al. } \\
\text { 2017) }\end{array}$ \\
\hline Cryptotanshinone & Diterpene & Salvia miltiorrhiza & $\times$ CLp and PLpro & $\begin{array}{l}\text { (Jiang et al. 2017; Chang et al. } \\
\text { 2018) }\end{array}$ \\
\hline Curcumin & Flavonoid & Curcuma longa & $\times$ virus replication and CLp & $\begin{array}{l}\text { (Wen et al. 2007; Cione et al. } \\
\text { 2020) }\end{array}$ \\
\hline Shikonin & Naphthoquinone & Lithospermum officinale & $\times \mathrm{CLp}$ & $\begin{array}{l}\text { (Jin et al. 2020; Mollaei et al. } \\
\text { 2019) }\end{array}$ \\
\hline Matrine & Alkaloid & Aspergillus terreus & $\begin{array}{l}\text { Improves altered parameters and } \\
\text { clinical symptoms }\end{array}$ & (Liu et al. 2021; Zhang et al. 2017) \\
\hline
\end{tabular}

Hinders $\times, H A$ hepatitis A, RLRs retinoic acid inducible gene I-like receptors, CLp chymotrypsin like protease, ACE2 angiotensin-converting enzyme

\section{COVID-19 vaccines}

Vaccines are necessary for controlling the severity and spreading of infection. There are many vaccination strategies tested in animals such as live attenuated virus, inactivated virus, recombinant DNA, viral vectors, subunit vaccines and protein vaccines. These studies are still continued and can take months or years to complete. Nowadays researchers are busy in developing vaccines against pandemic COVID-19 but the process of making a new drug entity and a vaccine is time taking (Khanal et al. 2021). Most of the antiCOVID-19 vaccines safety studies excludes older people due to associated comorbidities and weakness such as AstraZeneca, Moderna, and Pfizer have scarce data regarding vaccines safety in aged and sensitive individuals (Soiza et al. 2021). Centre for disease control and prevention (CDA) does not recommend one anti-COVID-19 vaccine over the other.

The detail of several COVID-19 vaccines, manufacturer, adverse effects, efficacy, safety, dose and their mechanism are mentioned in Table 4, Figs. 4 and 5. Whereas, efficacy (\%) of different available COVID-19 vaccines is shown in Fig. 6.

CoronaVac Sinovac vaccine denatured with aluminium hydroxide has progressed to phase 3 CT. It is fairly welltolerated and immunogenic in healthy people (Zhang et al. 2020) as shown in Fig. 4.

BNT162B1 The nucleic acid vaccines include mRNA and DNA vaccines. These vaccines are translated into viral pro- 
Fig. 3 A diagrammatic illustration of key targets for natural products as anti-COVID-19

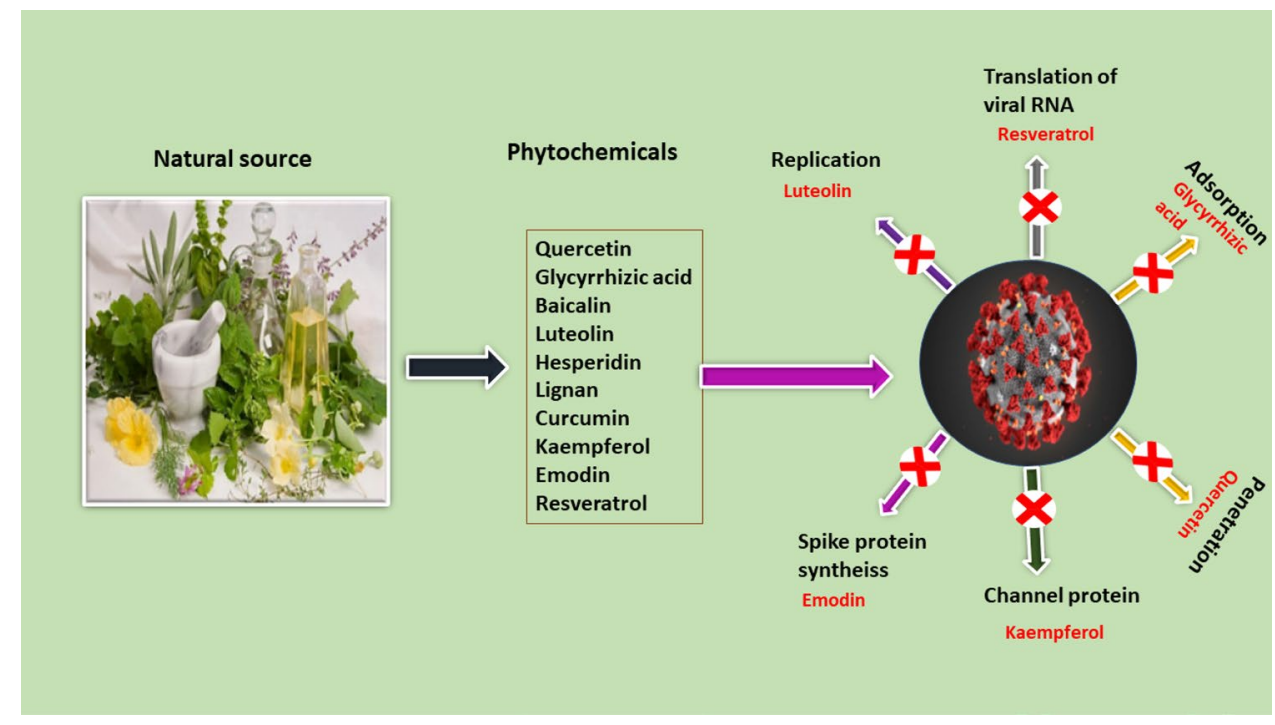

teins after injection. S protein has been the most popular candidate among COVID-19 proteins. Because of their high potency and potential to degrade quickly, mRNA vaccines are prospective substitutes to other vaccines (Wang et al. 2020b). In phase $1 / 2$ trials, BNT162B1 attacked the RBD of the $\mathrm{S}$ protein. The most vaccinators experienced mild to moderate systemic and local symptoms (Ewer et al. 2021). In phase $3 \mathrm{CT}$, a total of 43,548 people were randomly assigned, 21,720 were injected with BNT162b2 and 21,728 with placebo. In people 16 and older, a 2-dose treatment of it provided 95\% efficacy (Polack et al. 2020).

BioNTech (Pfizer) is the very first safe and effective vaccine which is authorized for emergency use in COVID-19, though, is not recommended by WHO in children below the age of 16 years. Due to paucity of safety data in pregnant and lactating women, it can be vaccinated in these women depending on risk benefit ratio.

mRNA1273 The two-dose vaccine sequence did not produce adverse effects and could elicit neutralization and Th1-biased CD4 + T-cell responses. The mode of action is shown in Fig. 4. According to a phase 1 trial, this vaccine was injected to a group and other group received placebo $(15,210$ members in each group) (Jackson et al. 2020). Its \% efficacy is 94.1 (Fig. 6).

Ad26COVS1 It is a recombinant transgenic vaccine consisting of adenovirus type5 (rAd5) and 26 (rAd26) (Logunov et al. 2020) as shown in Fig. 4. There were 19,630 SARS-CoV-2-negative respondents were inoculated with Ad26COV2S1 and 19,691 individuals who received placebo. It exhibited 73.1 in severe and $81.7 \%$ efficacy (Fig. 6) in critical Covid-19, respectively (Sadoff et al. 2021). The Janssen ( $\mathrm{J}$ and $\mathrm{J}$ ) is recommended for immunization against COVID-19 by WHO for people of 18 years and above. Preg- nant and lactating women can be vaccinated with J\&J on the basis of risk benefit ratio. It will not recommend in hypersensitive individual or having history of allergy to component of vaccine.

ChAd0x1 nCoV-19 The effectiveness, protection, and immunogenicity of a chimp adeno (ChAd)-vectored vaccine framework encoding the $\mathrm{S}$ protein with codon optimization were observed. It was found to be stable, tolerable, and immunogenic in a phase 1 and 2 CTs. Furthermore, acetaminophen should be concomitantly used as it alleviates adverse reactions such as pain, fever, and muscle ache in post-vaccinated individual (Folegatti et al. 2020) as mentioned in Table 4. The vaccine's overall efficacy was $70.4 \%$ (Voysey et al. 2021) as mentioned in Fig. 6.

AstraZeneca produced by Serum Institute of India and Republic of Korea is reviewed by European Medicine Agency (EMA) for safety, quality and efficacy and recommend its use for all people of 18 years and more. Pregnant and lactating women can be vaccinated with AstraZeneca on the basis of risk benefit ratio. It will not recommend in hypersensitive individual or having history of allergic reactions to any component of vaccine.

Sputnik V It is a vector vaccine that consists of rAd26 and rAd5 vaccine vectors, which is administered intramuscularly at 21-day intervals (Table 4). In the virus, the dsDNA coding for the spike protein is preserved. Infected cells produce the spike protein that triggers an immune reaction (immunogenicity). In Moscow, a phase 3 RCT with placebo control was carried in 25 hospitals and polyclinics. It prevented infection in $91.6 \%$ (Fig. 6) with no significant adverse effects except rash and immune reaction. Three severe adverse effects were identified in the vaccine community among participants above the age of 60 years 


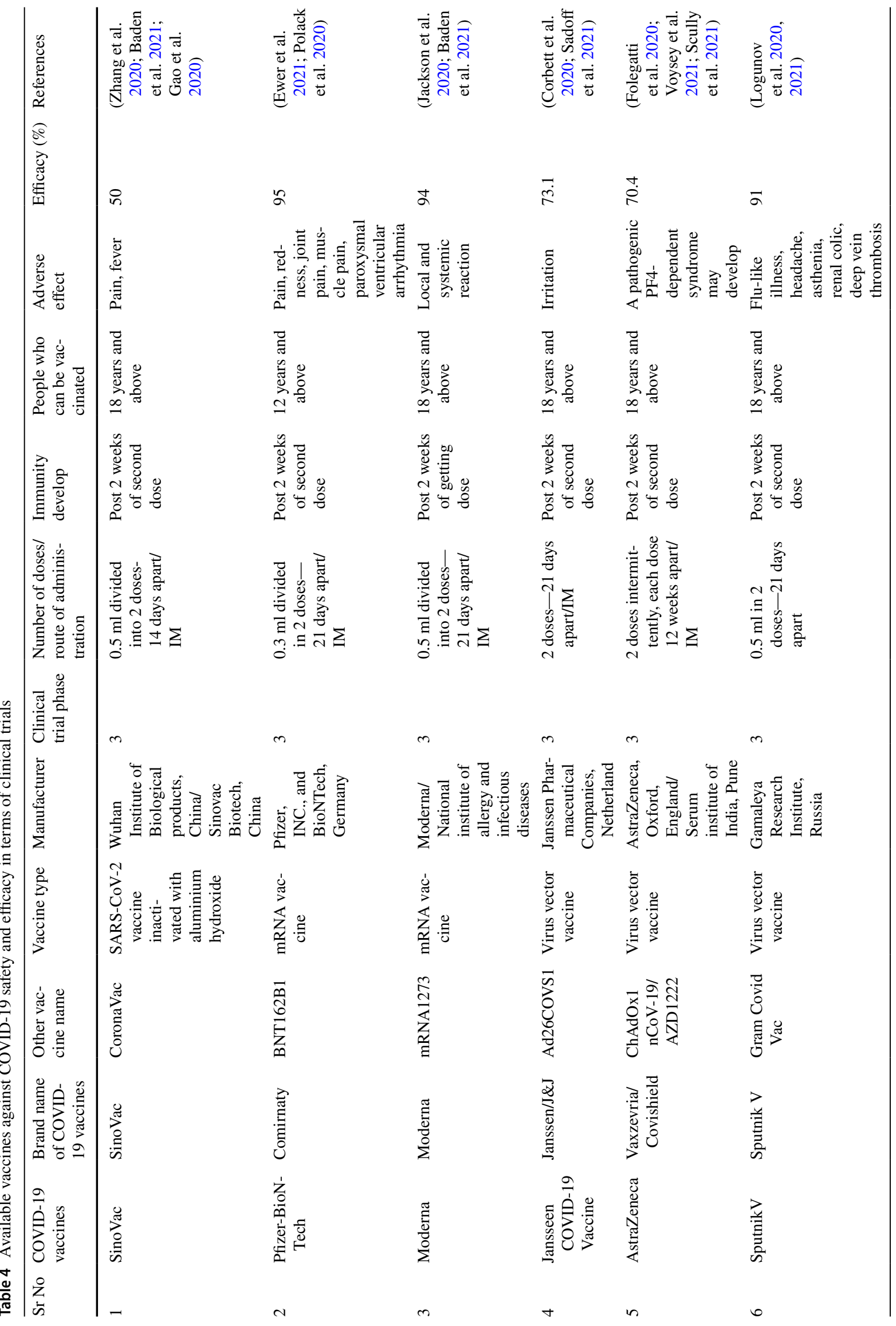




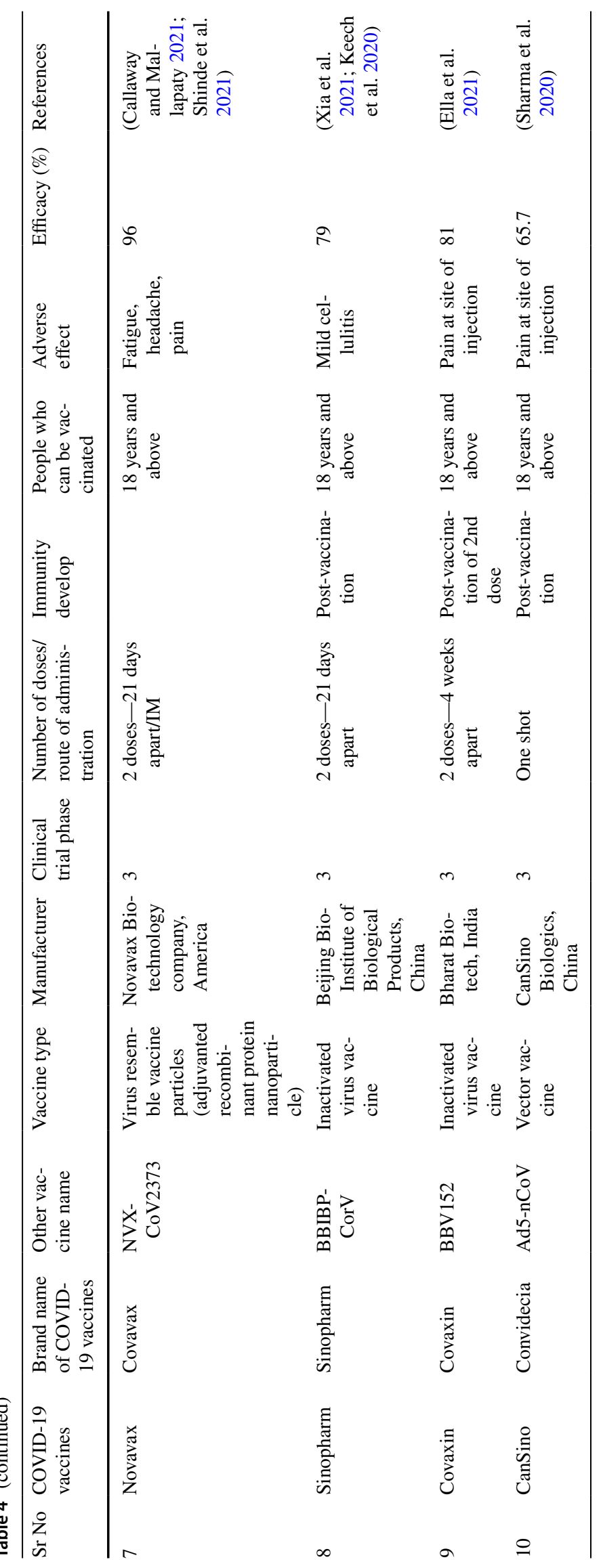




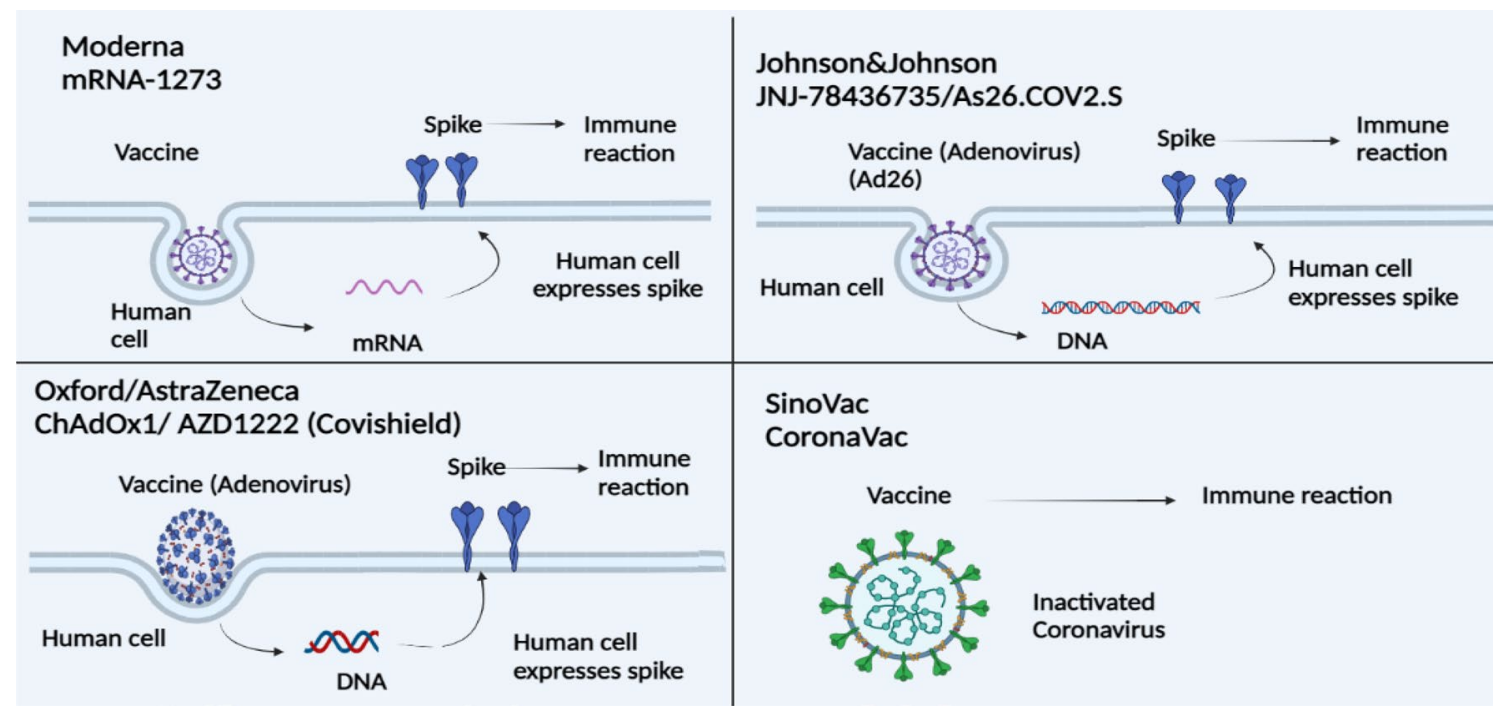

Fig. 4 Illustration of several COVID-19 vaccines and their mechanism ( modified from Dash et al. 2021)

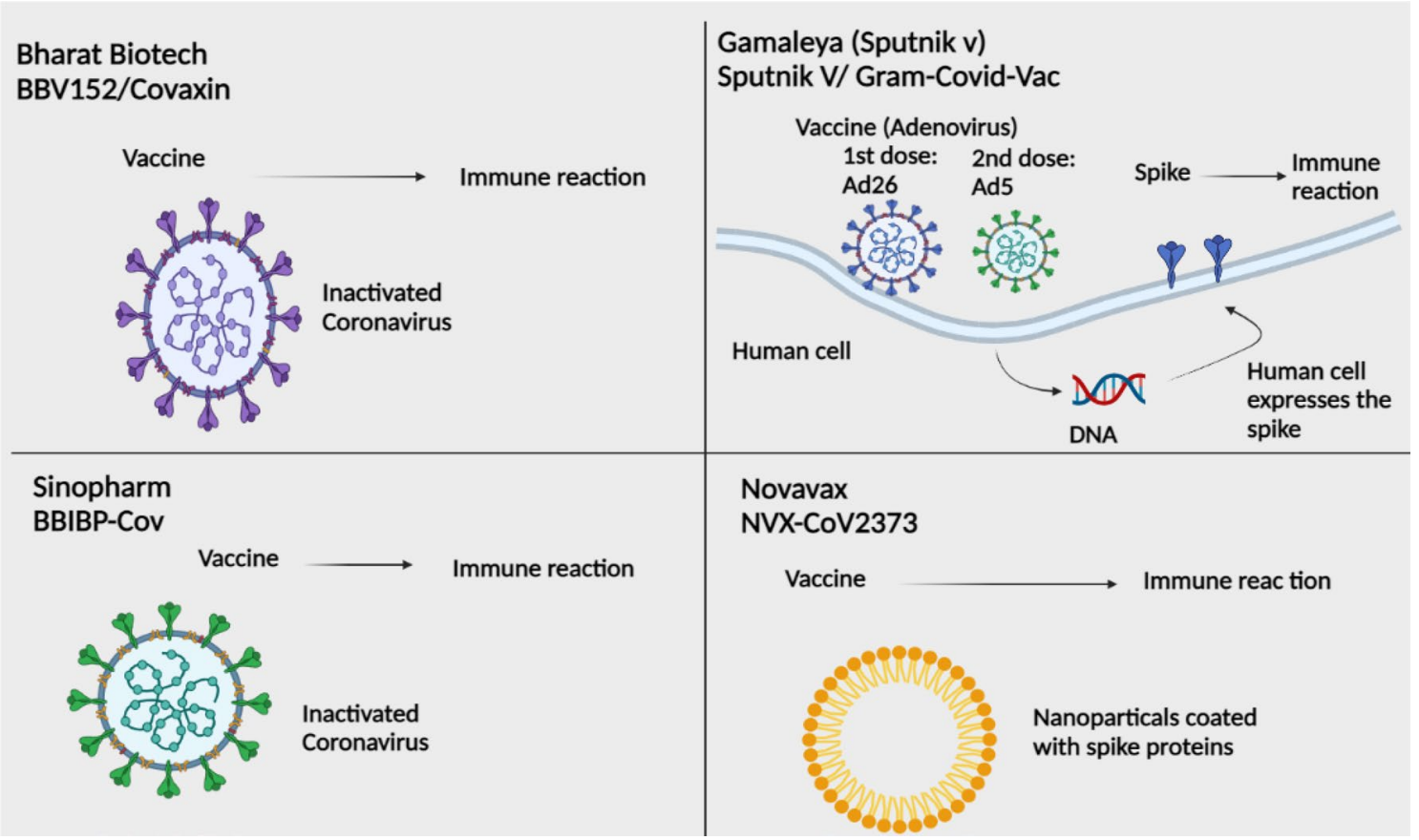

Fig. 5 Illustration of several COVID-19 vaccines and their mechanism ( modified from Dash et al. 2021)

included renal colic, deep vein thrombosis, and abscesses in the extremities as mentioned in Table 4 (Logunov et al. 2021). The mechanism of action of that vaccine is presented in Fig. 5.

EpiVac corona and CoviVac are the two other Russian vaccines that are approved by Russian Government for emergency use. These two vaccines are now under large scale CTs. EpiVac is synthetic peptide antigen while CoviVac contains inactivated cold virus.
BBIBP-CorV Inactivated or killed viruses can produce native antigenic epitopes (binding to $\mathrm{T}$ - and $\mathrm{B}$-cell antibodies) present in a stable and conformational manner (Delrue et al. 2012). BBIBP-CorV is manufactured by Beijing Bio-Institute of Biological Products (BBIBP). In BBIBP-CorV vaccine, SARS-COV-2 is chemically inactive (with betapropiolactone), thus it cannot replicate but all of the protein is still intact. The Shangqiu City, China, conducted a phase $1 / 2 \mathrm{RCT}$ of this vaccine in comparison 
Fig. 6 Graphical representation of percentage efficacy of different COVID-19 vaccines

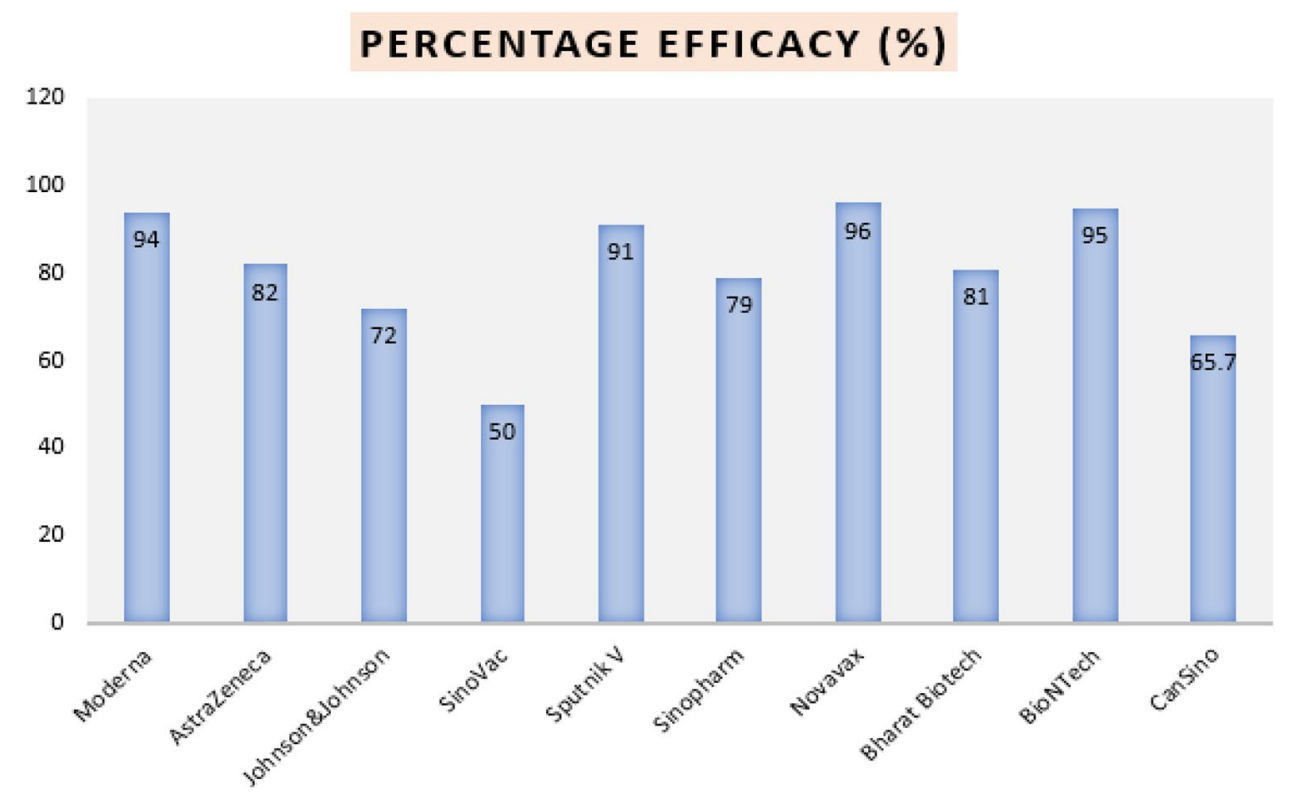

to placebo control. The trial involved healthy individuals (aged 18-80 years) in phase 1 and adult individuals (aged 18-59 years) in phase 2 . It is safe and well tolerated at all tested doses and presented $79 \%$ efficacy against Covid-19 (Xia et al. 2021).

Sinopharm Vac (BBIBP-CorV) is still not authorized/ reviewed by world's chief drug regulatory authorities such as the FDA, European Medicine Agency (EMA) and the United Kingdom's Medicines and Healthcare products. WHO has authorized its use for emergency in adults of above 18 years on May 7, 2021. The commonly reported minor adverse effects of Sinopharma Vac in individuals aged 19-59 are fever, headache, allergy, pain, and swelling at injection site while serious includes nausea, facial nerve symptoms, clot formation, and acute disseminated encephalomyelitis. The WHO holds serious concerns over age gap for safety study of Chinese vaccine. There are various controversies about safety and efficacy of that Vac because of the lack of CT data regarding individuals above 60 years of age. Aluminium hydroxide is used as adjuvant in Sinopharma Vac that strengthens the host's immune system for incorporated vaccine (Baraniuk 2021; Crasto 2021).

NVX-CoV2373 Another strategy for vaccine production is to use protein $\mathrm{S}$ as a recombinant protein subunit. This approach may protect immunized cells in vitro, but it has the potential to produce a polarized immune response in humans. Novavax, a vaccine uses adjuvant Matrix- $\mathbf{M}^{\mathrm{TM}}$ to improve immune response and has efficacy of $96 \%$ in COVID-19 patients under clinical trials phase 3 (Callaway and Mallapaty 2021). The most reported adverse effects among vaccine recipients were headache and muscle pain (Shinde et al. 2021).
BBV152 It is known as Covaxin manufactured by Bharat Biotech, India. It is an inactivated SARS-CoV-2 vaccine. At nine hospitals in India, a double-blind, RCT phase 2 was conducted to assess its immunogenicity and efficacy in healthy individuals (12-65 years). It induced strong neutralizing antibody responses in the phase 1 trial, which were raised 3 months later in all individuals. It showed enhanced reactogenicity, adaptive immunity and protection in phase 2 CT (Ella et al. 2021). It exhibits $81 \%$ efficacy against COVID-19 original strain in phase 3 CT (Fig. 6). The mechanism of action is presented in Fig. 5.

Ad5-nCoV/CanSino It is another corona vaccine manufactured by CanSino Biologics, China. It has $65.7 \%$ efficacy. It is single shot vaccine with similar efficacy to other vector vaccines like J\&J, Gamaleya, AD26. It is recommended for people 18 years of age and above (Sharma et al. 2020).

\section{Rare adverse effects of COVID-19 vaccines}

Janssen ( $\mathrm{J}$ and $\mathrm{J}$ ) was the very first, safe, and effective (older too) vaccine tool authorized for use by WHO and European Medicine Agency (EMA) in all countries, a step forward to combat COVID-19. On 13 Apr 2021, US regulatory agency temporarily restricted the use of $\mathrm{J}$ and $\mathrm{J}$ vaccine due to rarely reported adverse effects such as thrombosis and thrombocytopenia. The European regulators also reported thrombosis and thrombocytopenia with AstraZeneca vaccine in the same week. Blood clotting occurred mainly in veins of the brain and abdomen. Arteries are also affected in some cases, nevertheless the exact mechanism of thrombosis is ambiguous. Blood clotting is reported with AstraZeneca especially in women below 
60 years of age within 2 weeks of vaccination. Heparin induced thrombocytopenia is also rarely reported adverse event among patients taking heparin (anticoagulants). HIT is also reported even in those individual who are not taking heparin (Greinacher et al. 2021).

Schultz and coworker (2021) conducted a study on healthcare workers (aged 32-54 years) receiving AstraZeneca and reported venous thrombosis in 5 out of 130,000 vaccinated workers, who had not taken heparin. Moreover, the high titer of antibodies to platelet factor-4-polyanion complex was reported in those workers (Schultz et al. 2021). The regulators and researchers still recommend the use of AstraZeneca because the benefits of this vaccine outweigh the risks. The regulators and researchers still recommend the use of AstraZeneca vaccine because benefits outweigh the risks. Although several countries restrict its use in specific age groups, some countries hold its.

Both are adenovirus vector vaccines encoding the corona spike protein in human cells. The human cell uses this DNA information for the synthesis of more spike protein that develops ultimately develops an immune reaction against it (Ledford 2021). There is a lack of HIT like reaction in recipients of mRNA vaccines. Another vaccine, Sputnik V containing a different adenovirus vector has also exhibited a rare blood clot formation reaction. Various factors influence the blood clot formation with different adenovirus vector containing vaccines (AstraZeneca, J and J, and Sputnik V) such as different viruses used, cells type in which they are produced, and number of spike protein they carry, the mode of their purity, and dose of administration (Baraniuk 2021).

A study conducted on 64,503 COVID-19 patients showed that the prevalence of venous thromboembolism (VTE) was $14.7 \%$, pulmonary embolism and deep vein thrombosis was 7.8 and $11.2 \%$, respectively. The occurrence of VTE in COVID-19 hospitalized patients ranged from 0-69\% (Tan et al. 2021). Although exact mechanism of arterial VTE in COVID-19 patients is still unclear yet the contribution of systemic and endothelial inflammation activating factors, vascular coagulopathy, fibrinogen, factor VIII action, hypoxemia, and antiphospholipid antibodies response are evident (Vickers et al. 2017).

Virologists are currently working on the effect of various vaccines in vitro on vascular cells. The identification of trigger for that rare thrombosis effect is a key safety issue for the development of future vaccines. There is an immense need to sort out either we have to rely on adenovirus vaccines or turn towards mRNA vaccine development.

The CDC has reported rare adverse effects such as pericarditis and myocarditis with mRNA COVID-19 vaccines (BioNTech and Moderna) in adolescent and young individuals but vaccine's benefits outweigh the rarely reported potential risks and BioNTech is recommended for 12 years and older (https://www.cdc.gov).
The additives and adjuvants used in COVID-19 vaccines may impart crucial role in causing rare and common adverse effects. Immunologists are unsure whether vectors, contamination in vectors or spike protein are responsible for antibody formation against platelet factor-4 in HIT. Allergic reactions occur mostly due to excipients/adjuvant rather than active moiety (Kounis et al. 2021). Allergic reactions either major or minor are encountered with vaccines likewise other medications. Anaphylactic reactions, often are life threating and rarely occurring allergic reactions, are occasionally instigated due to inert material called excipients used in vaccine formulation to heighten palatability, absorption, stability, solubility, etc. Polyethylene glycol is used as excipient in BioNTech and Moderna vaccines while Polysorbate-80 used in AstraZeneca and J and J COVID-19 vaccines. In a previous study, the prevalence of allergic reactions was reported to be 1.31 out of a million vaccinated individuals, age and sex were equally contributing factors but females were appeared to be more sensitive in this regard (Kounis et al. 2021).

Adjuvants have been using in vaccines formulation for a long time, Aluminum salt based adjuvants (Alum) are the first recommended adjuvants for human use vaccines because of their consolidating effect on the immune response and good safety record (Liang et al. 2020). Adjuvants are also responsible for post vaccination adverse events. Aluminium hydroxide used as adjuvant in SARS coronavirus vaccine comprising of inactivated (by formalin or beta propiolactone) virus exhibited lung immunopathology in a previous study carried on mice (Tseng et al. 2012). Al salts also exhibited neurotoxicity and led to autoimmune reactions (Shaw et al. 2014; Danielsson and Eriksson 2021; Shoenfeld and Agmon 2011).

\section{Conclusion}

Allopathic medications cause acute toxicity in patients, which reduces the benefits of antiviral drugs and that risk exacerbates in patients with underlying heart or liver diseases. This toxicity risk prompts patient noncompliance and switch towards the alternative medicines that have lower side effects as compared to pharmacological drugs. Despite immense efforts and studies in the field of drug repurposing, significant roadblocks remain in the way of widespread use of repurposed medications, including problems with clinical dosage, safety, and delivery capabilities. Due to differences in choice of alternative medicines and lack of standardized data of the investigated formulations, it is currently difficult to draw information from the past studies. Nonetheless, there is inadequate evidence of significant antiviral effects unique to the SARS-CoV-2 virus. To determine their role in COVID-19 treatment, 
further research is needed to evaluate the detail mechanism regarding anti-inflammatory and immunomodulatory effects, and also the safety and quality of herbal medicines should be studied in COVID-19 patients/healthy individuals. Furthermore, there is an immense need to sort out more vaccines against COVID-19 with $98-99 \%$ efficacy that should be cheap and safe in use. The clinical trials of available vaccines should be conducted on a large group of participants, including pregnant and lactating females as well as children of different age groups as there is no single COVID-19 vaccine for maternal and children below 12 years of age. The safety profile of vaccine is crucial in the success of any vaccination program. Vaccine pharmacovigilance is playing a significant role in finding out a safe antiCOVID-19 vaccine that had developed. There is massive demand of robust vigilance system to find and resolve untoward effects linked to anti-COVID-19 vaccine. Due to complicated safety and efficacy concerns, CDA does not recommend one anti-COVID-19 vaccine over the other. Last but not the least, precautionary measures such as wearing mask and social distancing are better than getting infected. To date, there is no single curative treatment for this morbid and fatal virus.

Acknowledgements This study is not funded by any government and private agency.

Author contributions AS and MFA planned and designed the study. All authors contributed to data collection. AS and MFA wrote the manuscript. AS, MFA and MMAD critically reviewed and revised the manuscript. All authors read and approved the manuscript.

\section{Declarations}

Conflict of interest Authors declare no conflict of interest.

\section{References}

Adhikari B, Marasini BP, Rayamajhee B et al (2021) Potential roles of medicinal plants for the treatment of viral diseases focusing on COVID-19: a review. Phytother Res 35:1298-1312

Al Hamdany A, Al-Khatib A, Al-Sadi H (2019) An overview of the beneficial effects of qurecitin on bone. Int Med J 26(2):142-145

Baden LR, El Sahly HM, Essink B et al (2021) Efficacy and safety of the mRNA-1273 SARS-CoV-2 vaccine. N Engl J Med 384:403-416

Baig AM, Khaleeq A, Ali U et al (2020) Evidence of the COVID-19 virus targeting the CNS: tissue distribution, host-virus interaction, and proposed neurotropic mechanisms. ACS Chem Neurosci 11:995-998

Baraniuk C (2021) Covid-19: What do we know about Sputnik V and other Russian vaccines? BMJ 372: n743

Beck BR, Shin B, Choi Y et al (2020) Predicting commercially available antiviral drugs that may act on the novel coronavirus (SARSCoV-2) through a drug-target interaction deep learning model. Comput Struct Biotechnol J 18:784-790
Biggioggero M, Crotti C, Becciolini A et al (2019) Tocilizumab in the treatment of rheumatoid arthritis: an evidence-based review and patient selection. Drug Des Dev Ther 13:57

Callaway E, Mallapaty S (2021) Novavax Covid vaccine protects people against variants. Nature 590:17

Chang JHM, Lin CH, Shibu MA et al (2018) Cryptotanshinone (Dsh003) from Salvia miltiorrhiza Bunge inhibits prostaglandin E2-induced survival and invasion effects in HA22T hepatocellular carcinoma cells. Environ Toxicol 33:1254-1260

Chen H-S, Qi S-H, Shen J-G (2017) One-compound-multi-target: combination prospect of natural compounds with thrombolytic therapy in acute ischemic stroke. Curr Neuropharmacol 15:134-156

Chen T, Fei C-Y, Chen Y-P et al (2021) Synergistic inhibition of SARSCoV-2 replication using Disulfiram/Eebselen and Remdesivir. ACS Pharmacol Trans Sci 4:898-907

Cione E, La Torre C, Cannataro R et al (2020) Quercetin, epigallocatechin gallate, curcumin, and resveratrol: from dietary sources to human microRNA modulation. Molecules 25:63

Consortium WST (2021) Repurposed antiviral drugs for COVID19-interim WHO SOLIDARITY trial results. N Engl J Med 384:497-511

Corbett KS, Flynn B, Foulds KE et al (2020) Evaluation of the mRNA1273 vaccine against SARS-CoV-2 in nonhuman primates. $\mathrm{N}$ Engl J Med 383:1544-1555

Crasto A M (2021). BBIBP-CorV, Sinopharm COVID-19 vaccine. new drug approvals. https://newdrugapprovals.org/2021/03/23/bbibpcorv-sinopharm-covid-19-vaccine/. Accessed on Apr, 12, 2021.

da Silva AA, Wiedemann LSM, Veiga-Junior VF (2020) Natural product's role against COVID-19. RSC Adv 10:23379-23393

Danielsson R, Eriksson H (2021) Aluminium adjuvants in vaccinesA way to modulate the immune response. Semin Cell Dev Biol 115:3-9

Dash P, Mohapatra S, Ghosh S et al (2021) A scoping insight on potential prophylactics, vaccines and therapeutic weaponry for the ongoing novel Coronavirus (COVID-19) pandemic-a comprehensive review. Front Pharmacol 11:2471

Daskaya-Dikmen C, Yucetepe A, Karbancioglu-Guler F et al (2017) Angiotensin-I-converting enzyme (ACE)-inhibitory peptides from plants. Nutrients 9:316

David J Cennimo M, FAAP, FACP, AAHIVS. (2020) What is the role of the IL-6 inhibitor tocilizumab (Actemra) in the treatment of coronavirus disease 2019 (COVID-19)? Available at: https://www.medscape.com/answers/2500114-197457/what-isthe-role-of-the-il-6-inhibitor-tocilizumab-actemra-in-the-treat ment-of-coronavirus-disease-2019-covid-19.

Delrue I, Verzele D, Madder A et al (2012) Inactivated virus vaccines from chemistry to prophylaxis: merits, risks and challenges. Expert Rev Vaccines 11:695-719

Ella R, Vadrevu KM, Jogdand H et al (2021) Safety and immunogenicity of an inactivated SARS-CoV-2 vaccine, BBV152: a doubleblind, randomised, phase 1 trial. Lancet Infect Dis 21:637-646

Enmozhi SK, Raja K, Sebastine I et al (2021) Andrographolide as a potential inhibitor of SARS-CoV-2 main protease: an in silico approach. J Biomol Struct Dyna 39(9):3092-3098

Ewer KJ, Barrett JR, Belij-Rammerstorfer S et al (2021) T cell and antibody responses induced by a single dose of ChAdOx $1 \mathrm{nCoV}$ 19 (AZD1222) vaccine in a phase $1 / 2$ clinical trial. Nat Med 27:270-278

Fasuan TO, Gbadamosi SO, Akanbi CT (2018) Modification of amaranth (Amaranthus viridis) starch, identification of functional groups, and its potentials as fat replacer. J Food Biochem 42:e12537

FehrPSMBickertson AHJE et al (2015) An overview of their replication and pathogenesis; section 2 genomic organization. Methods Mol Biol Springer 1282:1-23 
Felsenstein S, Herbert JA, McNamara PS et al (2020) COVID-19: immunology and treatment options. Clin Immunol 215:108448

Folegatti PM, Ewer KJ, Aley PK et al (2020) Safety and immunogenicity of the ChAdOx1 nCoV-19 vaccine against SARS-CoV-2: a preliminary report of a phase $1 / 2$, single-blind, randomised controlled trial. Lancet 396:467-478

Forni G, Mantovani A (2021) COVID-19 vaccines: where we stand and challenges ahead. Cell Death Differ 28:626-639

Fotovvat M, Radjabian T and Saboora A (2017) Tanshinone compositions in wild growing salvia Xantocheilla boiss of Iran. 6th National Congress on Medicinal Plants. 6th National Congress on Medicinal Plants.

Gao Q, Bao L, Mao H et al (2020) Development of an inactivated vaccine candidate for SARS-CoV-2. Science 369:77-81

Goodarzi S, Tabatabaei MJ, Mohammad Jafari R et al (2020) Cuminum cyminum fruits as source of luteolin-7-O-glucoside, potent cytotoxic flavonoid against breast cancer cell lines. Nat Prod Res 34:1602-1606

Greinacher A, Thiele T, Warkentin TE, Weisser K et al (2021) Thrombotic thrombocytopenia after ChAdOx $1 \mathrm{nCov}-19$ vaccination. New Engl J Med 384:2092-2101

Harrison C (2020) Coronavirus puts drug repurposing on the fast track. Nat Biotechnol 38:379-381

Hasan M, Bae H (2017) An overview of stress-induced resveratrol synthesis in grapes: perspectives for resveratrol-enriched grape products. Molecules 22:294

He LL, Gong PY, Feng Y et al (2020) Analysis on application of Chinese materia medica in treatment of COVID-19 by suppressing cytokine storm. Chin Tradit Herbal Drugs 6(51):1375-1385

Hirai M, Matsuoka H, Syafruddin D et al (2015) Publications from Juntendo University Graduate School of Medicine, 2015 [6/6]. Health 43:53-61

Hoffmann M, Kleine-Weber H, Schroeder S et al (2020) SARS-CoV-2 cell entry depends on ACE2 and TMPRSS2 and is blocked by a clinically proven protease inhibitor. Cell 181:271-280.e8

Hordyjewska A, Ostapiuk A, Horecka A et al (2019) Betulin and betulinic acid: triterpenoids derivatives with a powerful biological potential. Phytochem Rev 18:929-951

Hu G, Peng C, Xie X et al (2017) Availability, pharmaceutics, security, pharmacokinetics, and pharmacological activities of patchouli alcohol. Evid Based Complement Alter Med 2017:1-7

Huang F, Li Y, Leung EL-H et al (2020) A review of therapeutic agents and Chinese herbal medicines against SARS-COV-2 (COVID19). Pharmacol Res: 104929.

Hulswit RJ, Lang Y, Bakkers MJ et al (2019) Human coronaviruses OC43 and HKU1 bind to 9-O-acetylated sialic acids via a conserved receptor-binding site in spike protein domain A. Proc Natl Acad Sci 116:2681-2690

Jackson LA, Anderson EJ, Rouphael NG et al (2020) An mRNA vaccine against SARS-CoV-2 - preliminary report. New Engl J Med 383(20):1920-1931

Jia HP, Look DC, Shi L et al (2005) ACE2 receptor expression and severe acute respiratory syndrome coronavirus infection depend on differentiation of human airway epithelia. J Virol 79:14614-14621

Jiang G, Liu J, Ren B et al (2017) Anti-tumor and chemosensitization effects of Cryptotanshinone extracted from Salvia miltiorrhiza Bge. on ovarian cancer cells in vitro. J Ethnopharmacol 205:33-40

Jiang Y, Yin W, Xu HE (2021) RNA-dependent RNA polymerase: structure, mechanism, and drug discovery for COVID-19. Biochem Biophys Res Commun 538:47-53

Jin C-C, Zhang J-L, Song H et al (2019) Boosting the biosynthesis of betulinic acid and related triterpenoids in Yarrowia lipolytica via multimodular metabolic engineering. Microb Cell Fact 18:1-18
Jin Z, Du X, Xu Y et al (2020) Structure of M pro from SARS-CoV-2 and discovery of its inhibitors. Nature 582:289-293

Joshi RS, Jagdale SS, Bansode SB et al (2021) Discovery of potential multi-target-directed ligands by targeting host-specific SARSCoV-2 structurally conserved main protease. J Biomol Struct Dynam 39(9):3099-3114

Karuppaiya P, Tsay HS (2020) Enhanced production of podophyllotoxin, kaempferol, and quercetin from callus culture of Dysosma pleiantha (Hance) Woodson: an endangered medicinal plant. Biotechnol Appl Biochem 67:95-104

Keech C, Albert G, Cho I et al (2020) Phase 1-2 trial of a SARS-CoV-2 recombinant spike protein nanoparticle vaccine. N Engl J Med 383:2320-2332

Kempuraj D, Thangavel R, Kempuraj DD et al (2021) Neuroprotective effects of flavone luteolin in neuroinflammation and neurotrauma. BioFactors 47:190-197

Khan S, Siddique R, Shereen MA et al (2020) Emergence of a novel coronavirus, severe acute respiratory syndrome coronavirus 2: biology and therapeutic options. J Clin Microbiol 58(5):e00187-20

Khanal P, Duyu T, Patil B et al (2021) In silico screening of JAK-STAT modulators from the antiviral plants of Indian traditional system of medicine with the potential to inhibit 2019 novel coronavirus. 3 Biotech 11(3): 1-18

Kishore V, Sastry Yarla N, Bishayee A et al (2017) Multi-targeting andrographolide and its natural analogs as potential therapeutic agents. Curr Top Med Chem 17:845-857

Kounis Ng, Koniari I, De Gregorio C et al (2021) Allergic reactions to current available COVID-19 vaccinations: pathophysiology, causality, and therapeutic considerations. Vaccines 9:221-239

Kumar S, Yadav M, Yadav A et al (2017) Antiplasmodial potential and quantification of aloin and aloe-emodin in Aloe vera collected from different climatic regions of India. BMC Complement Altern Med 17:1-10

Lai C-C, Shih T-P, Ko W-C et al (2020) Severe acute respiratory syndrome coronavirus 2 (SARS-CoV-2) and coronavirus disease-2019 (COVID-19): the epidemic and the challenges. Int J Antimicrob Agents 55:105924

Lammers T, Sofias AM, van der Meel R et al (2020) Dexamethasone nanomedicines for COVID-19. Nat Nanotechnol 15:622-624

Ledford H (2021) COVID vaccines and blood clots: five key questions. Nature 592:495-496

Lee HJ, Lee HK, Lim E et al (2015) Synergistic effect of lignin/polypropylene as a compatibilizer in multiphase eco-composites. Compos Sci Technol 118:193-197

Li W, Hulswit RJ, Kenney SP et al (2018) Broad receptor engagement of an emerging global coronavirus may potentiate its diverse cross-species transmissibility. Proc Natl Acad Sci 115:E5135-E5143

Liang Z, Zhu H, Wang X et al (2020) Adjuvants for coronavirus vaccines. Front Immunol 11:2896

Lin S-C, Ho C-T, Chuo W-H et al (2017) Effective inhibition of MERSCoV infection by resveratrol. BMC Infect Dis 17:1-10

Liu F, Li Y, Yang Y et al (2021) Study on mechanism of matrine in treatment of COVID-19 combined with liver injury by network pharmacology and molecular docking technology. Drug Delivery 28:325-342

Logunov DY, Dolzhikova IV, Zubkova OV et al (2020) Safety and immunogenicity of an rAd26 and rAd5 vector-based heterologous prime-boost COVID-19 vaccine in two formulations: two open, non-randomised phase 1/2 studies from Russia. Lancet 396:887-897

Logunov DY, Dolzhikova IV, Shcheblyakov DV et al (2021) Safety and efficacy of an rAd26 and rAd5 vector-based heterologous primeboost COVID-19 vaccine: an interim analysis of a randomised controlled phase 3 trial in Russia. Lancet 397:671-681 
Lu R, Zhao X, Li J et al (2020) Genomic characterisation and epidemiology of 2019 novel coronavirus: implications for virus origins and receptor binding. Lancet 395:565-574

Luo P, Liu D, Li J (2020a) Pharmacological perspective: glycyrrhizin may be an efficacious therapeutic agent for COVID-19. Int J Antimicrob Agents 55:105995

Luo P, Liu Y, Qiu L et al (2020b) Tocilizumab treatment in COVID-19: a single center experience. J Med Virol 92:814-818

Lurie N, Saville M, Hatchett R et al (2020) Developing Covid-19 vaccines at pandemic speed. N Engl J Med 382:1969-1973

Majumder J, Minko T (2021) Recent developments on therapeutic and diagnostic approaches for COVID-19. AAPS J 23:1-22

Malik Z, Parveen R, Parveen B et al (2021) Anticancer potential of andrographolide from Andrographis paniculata (Burm. F.) Nees and its mechanisms of action. J Ethnopharmacol 272:113936

Mason RJ (2020) Pathogenesis of COVID-19 from a cell biology perspective. Eur Respir Soc 55:2000607

Mollaei S, Khanehbarndaz O, Gerami-Khashal Z et al (2019) Molecular identification and phytochemical screening of endophytic fungi isolated from Lithospermum officinale L. roots: a new source of shikonin. Phytochemistry 168:112116

Nazari S, Rameshrad M, Hosseinzadeh H (2017) Toxicological effects of Glycyrrhiza glabra (licorice): a review. Phytother Res $31: 1635-1650$

Nguyen TTH, Woo H-J, Kang H-K et al (2012) Flavonoid-mediated inhibition of SARS coronavirus 3C-like protease expressed in Pichia pastoris. Biotech Lett 34:831-838

Okoshi K, Uekusa Y, Narukawa Y et al (2021) Solubility enhancement of berberine-baicalin complex by the constituents of Gardenia Fruit. J Nat Med 75:76-83

Palasca O, Santos A, Stolte C et al (2018) TISSUES 2.0: an integrative web resource on mammalian tissue expression. Database 2018:1-12

Petramfar P, Hajari F, Yousefi G et al (2020) Efficacy of oral administration of licorice as an adjunct therapy on improving the symptoms of patients with Parkinson's disease, a randomized double blinded clinical trial. J Ethnopharmacol 247:112226

Pitocco D, Tartaglione L, Viti L et al (2020) SARS-CoV-2 and DPP4 inhibition: is it time to pray for Janus Bifrons? Diabetes Res Clin Pract 163:108162

Polack FP, Thomas SJ, Kitchin N et al (2020) Safety and efficacy of the BNT162b2 mRNA Covid-19 vaccine. N Engl J Med 383:2603-2615

Quer G, Radin JM, Gadaleta M et al (2021) Wearable sensor data and self-reported symptoms for COVID-19 detection. Nat Med 27:73-77

Rao YK, Vimalamma G, Rao CV et al (2004) Flavonoids and andrographolides from Andrographis paniculata. Phytochemistry 65:2317-2321

Ray S, Maunsell JH (2011) Different origins of gamma rhythm and high-gamma activity in macaque visual cortex. PLoS Biol 9:e1000610

Reche A, Kolse R, Gupta S et al (2020) Therapeutic options for COVID-19: Pandemic-a review. Int J Res Pharmaceut Sci 11(Special Issue 1). https://doi.org/10.26452/ijrps.v11iSPL1. 2802

Russell CD, Millar JE, Baillie JK (2020) Clinical evidence does not support corticosteroid treatment for 2019-nCoV lung injury. Lancet 395:473-475

Ryu YB, Jeong HJ, Kim JH et al (2010) Biflavonoids from Torreya nucifera displaying SARS-CoV 3CLpro inhibition. Bioorg Med Chem 18:7940-7947

Sadoff J, Gray G, Vandebosch A et al (2021) Safety and efficacy of single-dose Ad26. COV2. S vaccine against Covid-19. New Engl J Med 384(23):2187-2201
Schultz NH, SørvollI H, Michelsen AE et al (2021) Thrombosis and thrombocytopenia after ChAdOx1 nCoV-19 vaccination. New Engl J Med 384(22):2124-2130

Schwarz S, Wang K, Yu W et al (2011) Emodin inhibits current through SARS-associated coronavirus 3a protein. Antiviral Res 90:64-69

Scully M, Singh D, Lown R et al (2021) Pathologic antibodies to platelet factor 4 after ChAdOx1 $\mathrm{nCoV}-19$ vaccination. New Engl J Med 23:2202-2211

Selmi S, Rtibi K, Grami D et al (2017) Protective effects of orange (Citrus sinensis L.) peel aqueous extract and hesperidin on oxidative stress and peptic ulcer induced by alcohol in rat. Lipids Health Dis 16:1-12

Sharma O, Sultan AA, Ding H, Triggle CR (2020) A review of the progress and challenges of developing a vaccine for COVID-19. Front Immunol 11:2413

Shaw CA, Li D, Tomljenovic L (2014) Are there negative CNS impacts of aluminum adjuvants used in vaccines and immunotherapy? Immunotherapy 6(10):1055-1071

Shereen MA, Khan S, Kazmi A et al (2020) COVID-19 infection: origin, transmission, and characteristics of human coronaviruses. J Adv Res 24:91-98

Shinde V, Bhikha S, Hoosain Z et al (2021) Efficacy of NVX-CoV2373 covid-19 vaccine against the b. 1.351 variant. New Engl J Med

Shoenfeld Y, Agmon-Levin N (2011) 'ASIA'-autoimmune/inflammatory syndrome induced by adjuvants. J Autoimmun 36(1):4-8

Sim SK (2019) 4 Flavonoid glycosides, Medicinal plant glycosides. University of Toronto Press, p 55-62

Soiza RL, SciclunaC TEC (2021) Efficacy and safety of COVID-19 vaccines in older people. Age Ageing 50(2):279-283

Stebbing J, Phelan A, Griffin I et al (2020) COVID-19: combining antiviral and anti-inflammatory treatments. Lancet Infect Dis 20:400-402

Su H, Yao S, Zhao W et al (2020) Discovery of baicalin and baicalein as novel, natural product inhibitors of SARS-CoV-2 3CL protease in vitro. BioRxiv 209:236

Szopa A, Kokotkiewicz A, Klimek-Szczykutowicz M et al (2021) Different types of in vitro cultures of Schisandra chinensis and its cultivar (S. chinensis cv. Sadova): a rich potential source of specific lignans and phenolic compounds. Plant Cell and Tissue Differentiation and Secondary Metabolites: fundamentals and Applications: 309-336.

Tallei TE, Tumilaar SG, Niode NJ et al (2020) Potential of plant bioactive compounds as SARS-CoV-2 main protease (Mpro) and spike (S) glycoprotein inhibitors: a molecular docking study. Scientifica 2020

Tan B K, Mainbourg S, Friggeri A et al (2021) Arterial and venous thromboembolism in COVID-19: a study-level meta-analysis. Thorax.

Tseng CT, Sbrana E, Iwata-Yoshikawa, et al (2012) Immunization with SARS coronavirus vaccines leads to pulmonary immunopathology on challenge with the SARS virus. PLoS One 7:e35421

Udwadia ZF, Singh P, Barkate H et al (2021) Efficacy and safety of favipiravir, an oral RNA-dependent RNA polymerase inhibitor, in mild-to-moderate COVID-19: a randomized, comparative, open-label, multicenter, phase 3 clinical trial. Int J Infect Dis 103:62-71

Vickers ER, Mcclure DL, Naleway AL et al (2017) Risk of venous thromboembolism following influenza vaccination in adults aged 50 years and older in the Vaccine Safety Datalink. Vaccine 35:5872-5877

Vijayvargiya P, Garrigos ZE, Almeida NEC et al (2020) Treatment considerations for COVID-19: a critical review of the evidence (or lack thereof). Mayo Clin Proc 95(7):1454-1466

Voysey M, Clemens SAC, Madhi SA et al (2021) Safety and efficacy of the ChAdOx1 nCoV-19 vaccine (AZD1222) against 
SARS-CoV-2: an interim analysis of four randomised controlled trials in Brazil, South Africa, and the UK. Lancet 397:99-111

Walls AC, Park Y-J, Tortorici MA et al (2020) Structure, function, and antigenicity of the SARS-CoV-2 spike glycoprotein. Cell 181:281-292 e286

Wang Q, Zhang Y, Wu L et al (2020) Structural and functional basis of SARS-CoV-2 entry by using human ACE2. Cell 181:894-904 e899

Wang C, Li W, Drabek D et al (2020a) A human monoclonal antibody blocking SARS-CoV-2 infection. Nat Commun 11:1-6

Wang F, Kream RM, Stefano GB (2020b) An evidence based perspective on mRNA-SARS-CoV-2 vaccine development. Med Sci Monitor 26:e924700-924701

Wen C-C, Kuo Y-H, Jan J-T et al (2007) Specific plant terpenoids and lignoids possess potent antiviral activities against severe acute respiratory syndrome coronavirus. J Med Chem 50:4087-4095

Wong AH, Tomlinson AC, Zhou D et al (2017) Receptor-binding loops in alphacoronavirus adaptation and evolution. Nat Commun 8:1-10

Wu J, Shen J, Han Y et al (2021) Upregulated IL-6 indicates a Poor COVID-19 prognosis: a call for tocilizumab and convalescent plasma treatment. Front Immunol 12:455

Xia S, Zhang Y, Wang Y et al (2021) Safety and immunogenicity of an inactivated SARS-CoV-2 vaccine, BBIBP-CorV: a randomised, double-blind, placebo-controlled, phase 1/2 trial. Lancet Infect Dis 21:39-51

Xu Y, Lian D, Chen Y et al (2017) In vitro and in vivo antibacterial activities of patchouli alcohol, a naturally occurring tricyclic sesquiterpene, against Helicobacter pylori infection. Antimicrob Agents Chemotherap 61.

Yan H, Ma L, Wang H et al (2019) Luteolin decreases the yield of influenza $\mathrm{A}$ virus in vitro by interfering with the coat protein I complex expression. J Nat Med 73:487-496

Yu Y, Zhang Y, Wang S et al (2019) Inhibition effects of patchouli alcohol against influenza a virus through targeting cellular PI3K/ Akt and ERK/MAPK signaling pathways. Virol J 16:1-16

Yuan M, Wu NC, Zhu X et al (2020) A highly conserved cryptic epitope in the receptor binding domains of SARS-CoV-2 and SARS-CoV. Science 368:630-633

Zhang L, Liu Y (2020) Potential interventions for novel coronavirus in China: a systematic review. J Med Virol 92:479-490

Zhang Q, Li Y, Xu F et al (2017) Optimization of submerged fermentation medium for matrine production by Aspergillus terreus, an endophytic fungus harboring seeds of Sophora flavescens, using response surface methodology. Mycobiology 45:90-96

Zhang Y-J, Zeng G, Pan H-X et al (2020) Immunogenicity and safety of a SARS-CoV-2 inactivated vaccine in healthy adults aged 18-59 years: report of the randomized, double-blind, and placebo-controlled phase 2 clinical trial. Medrxiv 25:1026

Publisher's Note Springer Nature remains neutral with regard to jurisdictional claims in published maps and institutional affiliations. 